\title{
DIREITOS HUMANOS: SÍNTESE HISTÓRICA DOS DIREITOS DAS MINORIAS
}

\author{
José Ronaldo de Freitas Machado ${ }^{1}$
}

RESUMO: O artigo em apreço, tem como objetivo de seu estudo, abordar o tema Direitos Humanos: Síntese Histórica dos Direitos das Minorias. Assim, a priori, apresenta-se a Declaração Universal dos Direitos Humanos, tanto quanto sua funcionalidade e peso no que tange aos direitos das minorias, juntamente com a exposição do Pacto Internacional dos Direitos Civis e Políticos de (1966) e também o Pacto Internacional dos Direitos Econômicos Sociais e Culturais, que evoluíram a partir da Declaração Universal, na qual se reafirmaram os direitos de o cidadão como ser humano livre. Ademais, a pesquisa preocupa-se com a definição do que são "minorias" e como identificá-las. E, por conseguinte, é elencado quem de fato são as minorias e em qual espaço da sociedade estão inseridas. Por fim, pontua-se a importância de saber os direitos das minorias para a sociedade contemporânea, com o intuito de sanar a discrepância concernente neste assunto, e assim buscar o ideal de uma sociedade que vise a justiça de fato e seja mais fraterna para a reflexão apropriada e sua aplicação no processo do ensino-histórico e aprendizagem daqueles que almejam fazer a diferença na construção do saber do Direito. Consequentemente, ratifica-se que essa pesquisa, se preocupou em traçar seu estudo na metodologia qualitativa, através de documentos bibliográficos, que dissertaram acerca do tema e objetivo principal deste artigo, as minorias e seu contexto histórico-crítico, alinhavados com as relevantes contribuições, por meio de dissertações, artigos e recortes de revistas científicas, com suas reflexões a partir de grupos de trabalhos e livros, com vistas na proposta principal, a saber, os direitos das minorias.

Palavras-Chave: História. Direitos das Minorias. Declaração Universal dos Direitos Humanos. Pacto Internacional dos Direitos Civis e Políticos.

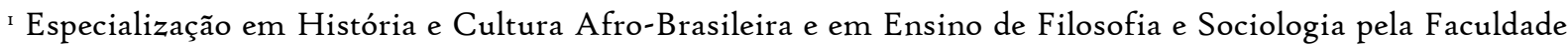
Venda Nova do Imigrante - (Faveni). Especialização em Direitos humanos e em Docência do Ensino Superior pelo Centro Universitário de Maringá - (Unicesumar). Especialização em Ciência da Religião pela Faculdade de Administração, Ciências, Educação e Letras - (Facel). Licenciatura em Geografia, em Letras/Inglês pelo Centro Universitário de Maringá - (Unicesumar). Licenciatura em Filosofia pela Universidade Metropolitana de Santos - (Unimes). Licenciatura em História pelo Centro Universitário de Jales - (Unijales). Bacharelado em Teologia pelo Centro Universitário de Maringá - (Unicesumar). Atuo como professor da Rede Estadual de Ensino do Estado de Minas Gerais. Leciono palestras nas áreas de Teologia, História, Docência e orientação de Metodologia Científica e Escritor.E-mail: pr.ronaldozoog@hotmail.com; Jr.ronaldoronaldo@gmail.com. Currículo Lattes: http://lattes.cnpq.br/8026976631953005.

ORCID: oooo-ooor-8416-259X.
} 


\section{INTRODUÇÃO}

O objetivo deste trabalho é descrever, refletir, contextualizar e sintetizar questões a respeito dos "Direitos das Minorias", que busca mediar informações históricas no processo da construção da sociedade Moderna, tanto quanto contemporânea, a respeito dos grupos minoritários existentes no mundo. Sendo assim, durante o desenvolvimento deste artigo, serão explanados pontos relevantes sobre a história dos Direitos constituídos das Minorias, a partir do documento da Declaração Universal dos Direitos Humanos de ro de dezembro de 1948.

Ademais, nesta pesquisa, além da Declaração Universal dos Direitos Humanos, serão observados apontamentos do Pacto Internacional dos Direitos Civis e Políticos (1966) que teve sua participação ativa para a compreensão e contextualização dos direitos de liberdade das minorias que sempre existiram no mundo, mas não eram amparadas em seus direitos pela sociedade desde o princípio do século XIX até atualidade. Haja vista, que o conhecimento a saber, sobre a temática em apreço, como a sociedade atual tenham evoluído, ainda trazem consigo marcas de descumprimentos destes direitos fundamentais, também, reconhecido como direitos humanos e suas regionalidades. Outrossim, este artigo terá o cuidado de explicitar a conceituação do termo "minoria", para que se possa reconhecê-la e respeitá-la como pessoas que merecem ser assistidas, defendidas, amparadas na forma da Lei.

Por conseguinte, tem-se como um dos objetivos específicos esta pesquisa facilitar, mediar, contextualizar o acesso ao conhecimento acerca da definição do referido termo, que está acessível a todos. Sabe-se que o tema minoria é de interesse do campo jurídico, pois, o que se espera de um Estado Democrático de Direito, é que todos sejam assistidos e protegidos pela Lei.

Para tanto, a pesquisa elencar-se-á quem de fato são os grupos minoritários em conformidade com a Lei e seus direitos constituídos pelo Estado Democrático de Direito. Dessa forma, a dissertação deste trabalho de pesquisa, contar-se-á com a metodologia bibliográfica, ou seja, uma pesquisa qualitativa, a partir de livros, dissertações, teses, 
publicações de artigos em revistas científicas, que se dispôs a tratar do assunto no estudo e prática do Direito.

Porquanto, em virtude das leituras, reflexões obtidas, apontamentos favoráveis encontrados nos materiais ora supracitados, poder-se-á elencar como se alcançou o lugar de fato de grupos minoritários e seus direitos. Entretanto, este artigo fará uma reflexão histórica dos direitos das minorias, sem nenhuma pretensão de estanque com respeito ao tema, que quanto mais é ponderado, pesquisado, sua abrangência tem sido cada vez maior.

\section{QUANDO SE PASSOU A PENSAR OS DIREITOS DAS MINORIAS}

Desde que, os poderes governamentais de um País, teve o entendimento a respeito do "direito", fez com que o procurassem e assim o sintetizassem de forma que alcançasse a todos os cidadãos. Pois, os Direitos Humanos, não implicam apenas em uma preocupação de não haver perda de um direito, uma violação. Mas sim também garantir a efetivação destes, não estando mais restrito a direitos de $\mathrm{I}^{\underline{a}}$ geração, no que se preza no Estado Democrático de Direito.

Ademais, sabe-se que o poder emana do povo, conforme a Constituição Federal de 1988, conforme reza no art. Io e no parágrafo único: “Todo o poder emana do povo, que o exerce por meio de representantes eleitos ou diretamente, nos termos desta Constituição" (CURIA; CÉSPEDES; ROCHA, 2016). Logo, todo ser humano é sujeito de diretos. Assim, é nesse contexto, que foi aclamado os “direitos humanos”, que já estavam inseridos os direitos das minorias, ou seja, dos grupos minoritários bastando, portanto, o reconhecido respeito, tanto quanto a proteção, pois, esse é assunto que será explicitado nesta pesquisa em seu desenvolvimento.

Os direitos das minorias alcançaram seu reconhecimento, por assim dizer, logo em seguida a Segunda Guerra Mundial, onde inúmeras barbáries foram cometidas, e por isso, impulsionou o início do debate acerca dos direitos do ser humano. A partir desse debate, elaborou-se o documento que preserva igualdade de todos os humanos perante a lei. Por conseguinte, ninguém deve sofrer retaliação porque a cor de sua pele é diferente, por sua etnia, pela sexualidade, nem muitos menos, pela sua religião professada, em conformidade com o que está redigido na Declaração Universal dos Direitos Humanos. Destarte, isso foi 
devido as atrocidades praticadas aos homens em relatos históricos sobre as guerras que marcaram a História da Humanidade, exterminando em massa pessoas inocentes, por questões socioeconômicas, políticas, culturais e religiosos.

Ainda sobre, conforme Faber (2015), a pior consequência, foi marcada no período da Segunda Guerra Mundial, pois, foi nesta guerra, onde a porcentagem de soldados quanto civis exterminados, chegaram a números assustadores, tudo por causa do poder. Não obstante, foi neste contexto, que 6 milhões de judeus foram conduzidos e assim dizimados nos campos de concentração nazistas, como também os ciganos, assim os eslavos, os poloneses, e por fim os homossexuais. Percebe-se, que os grupos expostos, pode ser entendido como minorias num país de domínio totalitário.

Não é de se admirar, que no século XXI, atitudes semelhantes ganham apoio de extremistas para tais práticas, por não aceitar o diferente, como àquele que está em pé de igualdade dos seus direitos como qualquer outro cidadão, indiferente do que se pensa a seu respeito. Acredita-se que: “A repetição dos discursos nos leva a uma prática da manutenção circular, esférica, dos conceitos e do próprio pensamento” declarou (SERRA, 2008, p. 24). Portanto, não é justo que caia em descrédito o que fora conquistado por meio de tantos debates, e embates sócio-políticos-econômicos e também religiosos.

\section{I.I DECLARAÇÃO UNIVERSAL DOS DIREITOS HUMANOS}

A respeito da Declaração Universal dos Direitos Humanos, não pretende que os seres humanos sejam reconhecidos como um, mas, dedicando parcela de seu texto justamente a resguardar o multiculturalismo. A declaração acima de tudo prega que devem ser respeitados os direitos de todos independente das diferenças, e assim gozem de liberdade de expressão do que são a partir da sua existência como ser humano sobre a terra. Portanto, com esse objetivo, desde o início da Declaração Universal, pode-se entender que:

Como o ideal comum a ser atingido por todos os povos e todas as nações, com o objetivo de que cada indivíduo e cada órgão da sociedade, tendo sempre em mente esta Declaração, se esforcem, através do ensino e da educação, por promover o respeito a esses direitos e liberdades, e, pela adoção de medidas progressivas de caráter nacional e internacional, por assegurar o seu reconhecimento e a sua observância universal e efetiva, tanto entre os povos dos próprios Estados-Membros, quanto entre os povos 
dos territórios sob sua jurisdição. (ASSEMBLEIA GERAL DA ONU, 1948).

Consoante, a observação em que a Declaração Universal, ratifica que o seu ápice é de alcançar o que é comum a todos na forma da Lei, indiferente de qualquer situação ou diferença entre os indivíduos, seja social, política, étnica, sexual ou religiosa. Por isso, entende-se que é importante o esforço de todos os países membros das Nações Unidas, para que se cumpra na base da Lei todos os direitos fundamentais, os direitos civis e econômicos de cada pessoa, seja individual ou no coletivo.

Ademais, a Declaração Universal dos Direitos humanos, nos apresenta palavras de relevância, grandeza e esperança, como se pode observar: "Todos os seres humanos nascem livres e iguais em dignidade e direitos. São dotados de razão e consciência e devem agir em relação uns aos outros com espírito de fraternidade" (ASSEMBLEIA GERAL DA ONU, 1948).

Após esta Declaração Universal, a Sociedade Internacional entendeu por bem, a necessidade de se firmar pactos internacionais, com intuito de fortalecer os Direitos que ela visa assegurar, uma vez que traz consigo em seus trinta artigos termos como "direito e direitos" mais de 50 vezes, visando a dignidade de cada pessoa. Todavia, cabe salientar que se trata de uma Declaração e, em geral as declarações não possuem força vinculante. Destarte, no caso da Declaração Universal, a doutrina tem compreendido que ela possui força por reconhecer direitos, correspondendo aos costumes e os princípios jurídicos internacionais. Em contra partida, Junior (2016, p. 26), verbaliza que não possui força em questões jurídicas externamente ditas, no que tange ao título de "Declaração", entretanto, somente de forma interna. Porém, ao assumir o termo doutrina, nesta pesquisa entende-se que:

\footnotetext{
A doutrina é bem mais que apenas a opinião dos doutos, chamados de juristas (communis opinio doctorum). E, acaba por ser considerada fonte, na lição de STOLZE e PAMPLONA FILHO pelo fato de continuamente propor soluções, inovar, interpretar e colmatar lacunas. (LEITE; CRUZ, 2020, p. I)
}

Portanto, os direitos previstos na declaração foram positivados na nossa constituição como Direitos fundamentais, e faz jus reclamar os direitos do cidadão, pois, o fato de ter nascido "livre" segundo consta na Declaração Universal, na Assembleia Geral da ONU 
(1948) lhe confere o direito à vida, saúde, educação, alimentação, segurança, proteção, dentre outros direitos que estão explícitos no art. $5^{\circ}$ da Constituição Federal de 1988.

\subsection{PACTO INTERNACIONAL DOS DIREITOS CIVIS E POLÍTICOS (1966)}

Na esteira da Declaração Universal dos Direitos Humanos têm-se dois pactos de grande relevância para essa pesquisa, que são: Pacto Internacional dos Direitos Civis e Políticos de 1966 e o Pacto Internacional dos Direitos Econômicos Sociais e Culturais do mesmo ano referido. Por conseguinte, o Pacto Internacional dos Direitos Civis e Políticos de 1966, em seu preâmbulo, corrobora muito com o que fora postulado pela "Declaração Universal". Com a intenção de reafirmar os direitos postulados nos documentos da Declaração e do Pacto de 1966, após leitura dos textos, pode-se perceber o peso legal de igualdade apontados em ambos. Ademais, chegou-se a declarar que os pontos principais, tinham um posicionamento genérico, porém, nada que pudesse ser confundido, e mal interpretado pelos países signatários.

No entanto, os detalhes que se julgavam ser necessário para que houvesse uma distinção melhor sobre os direitos do ser humano, foram especificados em outras “Convenções” a saber, Americana de Direitos Humanos e a Interamericana”, que primou por trazer a prevenção contra a tortura, tanto quanto, viabilizando-se em erradicar, prevenir, contrapor-se aos maus tratos, e a violência contra a mulher. Não obstante, chegou-se à conclusão que, a Declaração Universal, e os Pactos Internacionais Civis e Políticos e o dos Direitos Econômicos Sociais e Culturais, traziam consigo uma base amplamente fundamentada para a proteção dos direitos de cada ser humano, seja ele de grupos minoritários ou não, caberia ser assistido, protegido, defendido na forma da Lei.

Segundo Santiago (20II), o Pacto Internacional fora traçado com o intuito de prevenção, punição, como também, a erradicação à violência contra as mulheres, e demais minorias que viessem existir. A indagação a seguir: por que frisar sobre a violência contra a mulher? Pode soar obsoleta, porém, incontestavelmente a mulher era vista como alguém sem voz, logo, uma minoria, que não possuía força na sociedade, pois era rotulada como aquela que somente gera, cuida da casa, do marido e lhe deve respeito, porém, era abusada, maltratada, e, até mesmo, estuprada. Tal tratamento repulsivo, acontecia com frequência 
contra as mulheres, principalmente a mulher negra, que não era entendida como ser humano, mas, apenas uma escrava, objeto descartável, na sociedade antiga, tanto quanto, na atualidade.

Consequentemente, Santigo (20II) afirma que, nas legislações internas, haja vista, dos países signatários, “[...] é ainda carente de efetiva introjeção na cultura do povo brasileiro dos princípios defendidos por este documento, que buscam garantir a concretização de um Estado Democrático de Direito”. Seguramente, o Pacto Internacional ratifica os direitos dos seres humanos, e nos apresentam outra minoria: os negros, que por causa da cor de sua pele incomodava a sociedade da sua época. Por isso, historicamente, é mister destacar que na década de 1950-6o a luta racial foi intensa e esta preocupação com os negros é resultado dessa intensa luta do movimento negro, que marcou este período.

Haja vista, que em pleno século XXI o racismo ainda é vigente. No entanto, essa prática, conforme (NUNES, 2oro, p. 28), é "frequentemente chamada de racismo sutil". Porque, "o racismo claro e tradicional" tem sido condenado socialmente, destacou Nunes. Todavia, não se pode afirmar que essa condenação exclua que o racismo não exista. Sendo assim, interessa-se nesta pesquisa tecer comentários, de acordo o Pacto Internacional sobre a liberdade, reconhecendo que cada pessoa nasceu livre e possui direitos, termo postulado em toda Declaração Universal de 1948.

Portanto, após a libertação do temor e medo, conforme descrito no Pacto Internacional de 1966, é obrigatório, que as condições sejam ofertadas a cada um para que se aproprie dos seus direitos civis, tanto quanto políticos, também sociais e culturais, como todo ser humano que nasceu livre com direitos e deveres.

A partir dos pressupostos do Pacto Internacional, adquiriu-se maior compreensão a respeito dos direitos humanos, que mais tarde, em sua evolução, incorporariam os direitos das minorias, que estão alinhavados com base na premissa dos direitos fundamentais, que estão incluídos na Constituição Federal de 1988. Certamente por isso, que Silva (2006, p.6) declarou que: "Os Direitos Fundamentais, atualmente, são reconhecidos mundialmente, por meio de pactos, tratados, declarações e outros instrumentos de caráter internacional”.

Portanto, a esse respeito, apropria-se da contribuição, do art. $3^{\mathcal{O}}$ do Pacto Internacional, onde se afirma que: "Os Estados-partes no presente Pacto comprometem-se 
a assegurar a homens e mulheres igualdade no gozo de todos os direitos civis e políticos enunciados no presente Pacto”. Essa igualdade de direitos, há muito tempo, tem sido almejada por todos. Contudo, na sociedade vigente, tal prerrogativa parece ser uma utopia, porque, muito embora existam leis que resguardem isso, na práxis os direitos de muitas classes, ainda são violados.

Todavia, é fato pelo Estado Democrático de Direito, que todo cidadão deve ser tratado, assistido, acompanhado, defendido e cumprir seus deveres na base da Lei, conforme art. $5^{\circ}$ e incisos de I ao LXXVIII da Constituição Federal de 1988. Desse modo, Garcia (2004, p. 4), interpreta que: "A sociedade deve garantir o direito universal do cidadão, acrescido dos direitos específicos da minoria”.

\section{DEFINIÇÃO DO TERMO “MINORIAS”}

O termo minorias, não deve ser caracterizado como uma corrente de pensamento, onde é inserido adeptos, críticos, ou apenas formadores de opinião, que se autodenominam senhores da verdade absoluta da sociedade, pelos programas de entretenimento, por meio dos veículos de comunicação. Por isso, observa-se que de acordo com (MARTINS; MITUZANI, 20II, p. 320):

O tema "direito das minorias" revela-se indispensável para a compreensão
aprofundada da construção histórica da igualdade, da eficácia no plano jurisdicional
dos direitos fundamentais e das decisões proferidas a esse respeito.

Respeito esse, que se aplica a todos os cidadãos que compõe o Estado Democrático de Direito, conforme presente na Constituição Federal de 1988. Devido ao fato de o poder estar nas mãos de poucos, a história, nos afirmou que muitos conhecidos como minoria, desde sua chegada há este mundo, sofreram todo tipo de exclusão e atrocidades, onde poder-se-ia dizer, em linhas gerais, que foram vítimas de crimes hediondos.

Uma das definições do termo minoria é a "Inferioridade numérica; subgrupo de uma sociedade que, por ser diferente do grupo maior ou dominante, é alvo de discriminação e preconceito" segundo o dicionário Houaiss (2011, p. 637). Ainda, salienta-se a definição de minoria, como: 
O conceito de direito das minorias ora indicado é operativo; ele estipula a compreensão do "direito das minorias" a fim de analisar, mediante comparação, como estes direitos foram juridicamente proclamados pelas Nações Unidas em face de outros diplomas internacionais que também veiculam proibições de discriminação, sem referir-se a minorias. (RIOS; LEIVAS; SCHÄFER, 2017, p. 131)

Para tanto, o fato de não se mencionar quais seriam estas minorias, a citação que antecede este comentário, declara ser operativo ${ }^{2}$ e que se estipula a compreensão do "direito das minorias”, logo, se baseia na premissa maior da tutela dos direitos, que por fim ratifica a constitucional, direito de igualdade de ser assistido nos termos da Lei.

Por exemplo, é conhecido pelo Estado Democrático de Direito, que ninguém deve ser discriminado, ou excluído, por sua confissão religiosa, outrossim por causa de sua pele, ou ainda por sua vida sexual, e política, tendo em vista o que a Constituição Federal de 1988 declara a respeito, como segue-se:

Art. $5^{\mathfrak{o}}$ Todos são iguais perante a lei, sem distinção de qualquer natureza, garantindo-se aos brasileiros e aos estrangeiros residentes no País a inviolabilidade do direito à vida, à liberdade, à igualdade, à segurança e à propriedade, nos termos seguintes:

I - homens e mulheres são iguais em direitos e obrigações, nos termos desta Constituição;

II - ninguém será obrigado a fazer ou deixar de fazer alguma coisa senão em virtude de lei;

A priori, nesta pesquisa, já havia se posicionado sobre os direitos igualitários, ao homem, tanto quanto, a mulher, com base legal na Declaração Universal dos Direitos Humanos e o Pacto dos Direitos Civis e Políticos de (1966). Portanto, quando há ocorrência deste tipo de atitude, de discriminação, entende-se como crime de acordo com o disposto na Lei 7.716 de 5 de janeiro de 1989, no art. $\mathrm{I}^{\circ}$, que declara: "Serão punidos, na forma desta Lei, os crimes resultantes de discriminação ou preconceito de raça, cor, etnia, religião ou procedência nacional."

Não obstante, outro pressuposto de tamanha relevância a respeito das minorias fora verbalizado por Moreno (2009, p. 149):

A palavra minoria, inúmeras vezes aparece acompanhada de um adjetivo indicativo da origem da própria destinação. Ou seja, as minorias "nacionais",

${ }^{2}$ RIOS; LEIVAS; SCHÄFER, op. cit., p. I3I. 
“étnicas", "religiosas" e "linguísticas" estampam a própria proteção internacional das minorias e seus respectivos direitos.

Portanto, as minorias são dignas de igualdade em direito pelo Estado que é o regulador social de fato, tanto quanto por direito. Exatamente, por entender que a isonomia se aplica a todos na forma da Lei Maior e não deve haver distinção na sua aplicabilidade, mas coerência no que diz a Lei, de acordo com Sarmento \& Souza Neto (2012, p. 35 apud COURA; ESCOSSIA, 2015, p. 68) que afirmam "a proteção às minorias estigmatizadas".

Entretanto, muitas indagações são postuladas, com respeito há tantos crimes contra pessoas que são enxergadas como participantes das classes minoritárias? Para tanto, o questionamento continua: "O que elas representam na e para a sociedade em que se vive? Qual atitude dever-se-ia tomar contra os abusos a estas pessoas? Em nome de um pressuposto sentimento, amoroso, homens matam as mulheres? E o que dizer acerca das crianças, que sofreram e ainda sofrem tantos abusos psicológicos quanto físicos, principalmente de familiares, que deveriam protegê-las? Estas e muitas outras indagações continuam a retumbar na sociedade e as respostas são insatisfatórias.

Deveras, seria plausível que a sociedade entendesse a descrição de Marciel Neto (2007, p.47) que: “A justiça é um fim social, da mesma forma que a igualdade ou a liberdade ou a democracia ou um bem-estar". Por isso, a categoria minoritária, reclama seu direito de justiça quando é negligenciada, rotulada com base em sua etnia, classe social, gênero, dentre outros. Isso porque a justiça e o Direito são para todos. Nader (2009, p.43) afirma que o Direito: “[...] não é um fenômeno transitório, pois corresponde a necessidades sociais permanentes", sendo assim, tanto a justiça quanto o direito, se aplicam a todo ser humano para que a verdade seja alcançada.

Não obstante, a percepção que tem, é a falta de aceitação do conhecimento pela sociedade, no que diz respeito aos grupos minoritários. Certamente, é devido a não compreensão, de que todo ser humano, mereça ser feliz, livre, sem ser coagido por ninguém, por representar uma classe diferenciada das demais. Em suma, o assunto ora apreciado, faz com que nos lembre da "maiêutica" socrática, que debatia os pensamentos sofistas, que a certo modo, acreditava-se a pólis, serem os únicos mais sábios; e isso os descrevia como uma 
postura positivista, ou seja, “[...] uma espécie de primazia da ciência em detrimento de outras formas do conhecimento humano", descreveu Brandão (20II, p. 80).

Todavia, ainda sobre o tema, Sócrates deixou transparecer que: “[...] a parturição de ideias é tarefa primordial do filósofo, a fim de despertar nas almas o conhecimento" (BITTAR; ALMEIDA, 2005, p. 65). E, por isso, infere-se deste episódio, que ocorrera em meados do século $\mathrm{V}$ a. C., e interpreta-se que a sociedade da informação tem repetido os mesmos atos de ignorância com respeito a definição e reconhecimento dos direitos, das minorias, quando questionada.

Certamente, percebe-se que há incerteza nos dizeres, definições e reconhecimento dos "direitos das minorias". Pois, ainda que haja pluralidade de significados o termo "minoria” enseja-se, invariavelmente que o Judiciário proteja os grupos minoritários, fazendo valer os seus direitos prescritos na Constituição Federal de 1988.

Todavia, através do estudo de Direito, espera-se que àqueles que são vistos como diferentes pela sociedade, sejam respeitados, pelo que são: "seres humanos”. Pois, a ética determina as normas de conduta do indivíduo, seja qual for à sociedade que estiver inserido. Ademais, Melani (2016, p. 15) explica que: "Os homens filosofariam para se libertar da ignorância, buscando unicamente o conhecimento ou o saber". Para que, a posteriori, se entendesse o que é uma minoria, pois, a racionalidade entrar-se-ia em debate com os racionais.

\section{QUEM SÃO AS MINORIAS SEGUNDO O ESTUDO DO DIREITO}

As minorias são reconhecidas como os excluídos, discriminados, os desiguais em etnia, sexualidade, linguagem, e religiosidade na sociedade. Para tanto, a respeito das minorias, adiciona-se seguramente a definição de Rigaux (2003, p. 35-36 apud MARTINS; MITUZANI, 2011, p.327):

[...] conceitua como "todo grupo social detentor de traços relativamente indeléveis e cujos membros não poderiam por esse motivo fundir-se em uma população homogênea apta a gerar maiorias flexíveis e mutáveis. O pertencer ético, a língua, a fidelidade às tradições religiosas ou culturais que não são partilhadas pela maioria da população, a orientação sexual são alguns exemplos de traços próprios de um grupo social e que podem isolá-lo.[...] 
Consequentemente, as atitudes anormais, os discursos de ódio contra esses grupos são dignos de punição na forma da Lei. Pois, de acordo com (CINTRA; GRINOVER; DINAMARCO, 2006, p. 25): “A existência do direito regulador da cooperação entre pessoas é capaz da atribuição de bens a elas [...]”, logo, essa atribuição de bens, entende-se como, seus direitos garantidos e que não sejam injustiçados.

Por conseguinte, é compreendido pelo pesquisador Miranda (2020), que tais práticas são ensinadas, não nascem com os seres humanos. Ademais, Mandela (1995, p. 493 apud MIRANDA, 2020, p. 2), declarou que: "Ninguém nasce odiando outro pela cor de sua pele, por sua origem ou ainda por sua religião. Para odiar, as pessoas precisam aprender, e se podem aprender a odiar, elas podem ser ensinadas a amar". Entrementes, Nunes \& Júnior (2or4, p. 3), afirmaram que“[...] o que se percebe no Brasil, com maior veemência, é a discriminação contra afrodescendentes e índios”.

Porém, não apenas essas classes, mas a mulher, os homossexuais, os religiosos, os cidadãos de inclusão, dentre outras minorias, por si também, são expostos a ignomínia, na sociedade democrática, mesmo tendo seus direitos garantidos pela Constituição Federal de 1988, nos artigos $5^{\circ}$, $215^{\circ}$ em seu § Iㅇ e $216^{\circ}$. A esse respeito, Rocha (2003, p. 74) disse que: "A lei, sozinha, não é suficiente para fazer as grandes revoluções dos direitos humanos. Em sequência, ratificou: “[...] sou das que defendem que ele é necessário, mas precisa de um contexto, senão vira mero pretexto, inclusive desculpa para que não haja novas lutas. Desse modo, em concordância à luz do Direito, compreende-se a necessidade, quanto sua abordagem nesse assunto, minorias, considerando que os valores elencados como justificativa para discriminações, vieram a partir dos pressupostos e construções históricas do ser humano em sociedade.

Frequentemente, é nesse contexto, que se percebe a inversão da consciência do ser humano que compõe as massas ideologicamente. Decerto, essa inversão dos valores e direitos dos cidadãos, tem produzido "[...] a concepção do caráter alienador da ideologia em vista da inversão do conhecimento", bem dissera Paula (2014, p. 197), em que, a rejeição do outro, do outsider não é irracional, mas resultado de uma construção cultural. 
As pessoas reproduzem os preconceitos e discriminações pois estes são elementos essenciais para a perpetuação dos discursos hegemônicos e manutenção da ordem social posta. Ademais, a alienação produz a discriminação do diferente e sua exclusão, como costumava acontecer no âmbito da privação das liberdades religiosas, no início das discussões sobre as minorias. Contudo, foi a partir do "Tratado de Vestefália de 16483, concedeu determinados direitos, as minorias religiosas, porém, não a todas.

Haja vista, que a partir do século XVII, a expressão "proteção das minorias" era relevante, especial para os que julgavam-se ser participantes das minorias religiosas. No entanto, a posteriori, a atenção pela proteção dos seus direitos, focou nas minorias étnicas ou nacionais.

Portanto, mediante ao exposto, conclui-se possível declarar que o entendimento acerca das minorias passou a ser compreendido não apenas nas religiões, mas também, abrangendo, desse modo, as noções de identidade nacional ou étnica, cultural, e linguística das minorias, conforme descrito na Declaração Sobre os Direitos das Pessoas Pertencentes a Minorias Nacionais ou Étnicas, Religiosas e Linguísticas - 1992, em seu primeiro artigo. Todavia, salientar-se que o presente artigo, descreve brevemente a respeito das minorias do ponto de vista do estudo do Direito. Em síntese, define-se como algumas das minorias os seguintes grupos, segundo Alves (2009, p. 75):

\section{“[...] os indígenas e outras minorias étnicas distintas dos afrodescendentes, os portadores de necessidades especiais, as minorias linguísticas, as minorias religiosas, as minorias culturais, os povos de rua, as populações marginalizadas, os pobres, entre outros".}

As minorias supracitadas não são as únicas. $O$ rol das minorias é extenso, porém, neste artigo, não seria possível elencá-los, nem mesmo, se demorar no estudo de todas elas. “Certamente, por isso, optou-se por observar as minorias a partir da ótica da Declaração de I992", já mencionada.

Assim sendo, é transparente, que em todos os estudos referentes às minorias, ou grupos minoritários, o objetivo de estudo sempre foi a partir dos seres humanos, logo, são legalmente amparados por direitos individuais e coletivos, como quaisquer membros de uma

3 OS DIREITOS DAS MINORIAS. Módulos sobre Questões Selecionadas de Direitos humanos. pp. 467-50o. Disponível em: 〈http://www.igc.fd.uc.pt/manual/pdfs/O.pdf〉. Acesso em I3 de fev. 202I. 
sociedade democrática. A esse respeito, dissertou Reale (1999, p. 210): "O homem é o valor fundamental, algo que vale por si mesmo, identificando-se seu ser com a sua valia. De todos os seres, só o homem é capaz de valores [...]”.

Logo, segundo o art. $2^{\mathrm{o}}$ da Declaração Universal dos Direitos Humanos de io de dezembro de 1948, todos os humanos, sem “[...] distinção de qualquer espécie, seja de raça, cor, sexo, idioma, religião, opinião política ou de outra natureza, origem nacional ou social, riqueza, nascimento, ou qualquer outra condição", merecem respeito e ter garantidos seus direitos, pois todos são iguais perante a Lei.

\section{CONSIDERAÇÕES FINAIS}

Nesta pesquisa, objetivou-se traçar uma síntese histórico-crítico pelo estudo do direito das minorias, assunto que há tempos têm sido discriminados e postos por escanteio na sociedade, pelo simples fato de serem “diferentes”. Todavia, o trabalho em questão, não teve a pretensão de estancar o assunto, pois, o tema apreciado nesta pesquisa, ainda traz consigo inúmeras discussões para novas monografias, dissertações e artigos no campo de estudo do Direito.

Portanto, a premissa de maior escala deste estudo, teve seu nascedouro a partir das características históricas da Declaração Universal dos Direitos Humanos, como precursora dos direitos das classes minoritárias, juntamente com o Pacto Internacional dos Direitos Civis e Políticos de 1966 e também o Pacto Internacional dos Direitos Econômicos Sociais e Culturais

Com isso em mente, verificou-se o que a Declaração Universal dos Direitos Humanos disse acerca das minorias e como elas deveriam ser tratadas. Outrossim, se observou que a partir da Declaração, se construiu o Pacto de 1966, que reconheceu o direito das minorias a partir da noção de que todo ser humano nasce livre e é digno de respeito.

Ademais, com amparo na forma da Lei, ou seja, a "Carta Magna” sobre direitos individuais e fundamentais, se viu pronto em definir o termo minorias, ou grupos minoritários, como foi amplamente exposto nesta pesquisa, e assim destacar algumas delas e explicar o porquê de terem recebido essa nomenclatura. 
Além do mais, fora explicitado uma breve abordagem em síntese das minorias, com o intuito de sugerir que se faça uma reflexão acerca de seus direitos, quanto historicamente, para que se possa compreender o assunto, contextualizando-o ao atual cenário contemporâneo.

Certamente é compreensível, que quando se debruça sobre a questão das minorias, nos remete ao passado com vislumbre do presente, quando inúmeras pessoas foram dizimadas, abusadas, excluídas, envergonhadas e discriminadas unicamente por causa de sua crença, cor, gênero, dentre outras características.

Por fim, conhecer o passado é essencial para que se possa, no presente, não reproduzir os erros que foram cometidos as minorias, e assim fazer com que se cumpra o postulado pela Declaração Universal dos Direitos Humanos. Pois, todos nascem com direito de liberdade, igualdade e dignidade em direitos" conforme fora dissertado em todo desenvolvimento desta pesquisa, e que se reafirmou pelos Pactos Internacionais de I966 e pela Constituição Federal de 1988.

\section{REFERÊNCIAS}

ALVES, Fernando de Brito. Para Uma Fundamentação Dos Direitos De Minorias Em Tempos De Transição Paradigmática. 2009. 126 f. Dissertação (Mestrado em Ciência Jurídica) do Centro de Ciências Sociais Aplicadas do Campus de Jacarezinho da Universidade Estadual do Norte do Paraná, 2009. Disponível em: $\langle$ http://livrosor.livrosgratis.com.br/cpir4395.pdf〉. Acesso em 22 de janeiro 2019.

\section{BIBLIOTECA VIRTUAL DE DIREITOS HUMANOS. Declaração Sobre os Direitos das} Pessoas Pertencentes a Minorias Nacionais ou Étnicas, Religiosas e Linguísticas - 1992. Disponível

〈http://www.direitoshumanos.usp.br/index.php/Preven\% $\mathrm{C}_{3} \% \mathrm{~A}$ 7\% $\mathrm{C}_{3} \% \mathrm{~A}_{30-\text { contra-a- }}$ Discrimina\% $\mathrm{C}_{3} \% \mathrm{~A}_{7 \%} \mathrm{C}_{3} \% \mathrm{~A}_{30-e-P r o t e} \mathrm{C}_{3} \% \mathrm{~A}_{7} \% \mathrm{C}_{3} \% \mathrm{~A}_{30}$-das-Minorias/declaracaosobre-os-direitos-das-pessoas-pertencentes-a-minorias-nacionais-ou-etnicas-religiosas-elinguisticas.html >. Acesso em I3 de fev. de 2021.

BITTAR, Eduardo C. B.; ALMEIDA, Guilherme de Assis de. Curso de Filosofia do Direito. - 4. ed. São Paulo: Atlas, 2005.

BRANDÃO, Ana Rute Pinto. A Postura do Positivismo com relação as Ciências Humanas. Theoria - Revista Eletrônica de Filosofia, Volume 03 - Número o6 - Ano 20II. Disponível 
em: $\langle$ https://www.theoria.com.br/edicaoo6II/a_postura_do_positivismo.pdf $\rangle$. Acesso em I2 de fev. 2021.

CINTRA, Antonio Carlos de Araújo; GRINOVER, Ada Pellegrini; DINAMARCO, Candido Rangel. Teoria Geral do Processo. $26^{\mathrm{a}}$ edição revista e atualizada. São Paulo: Malheiros, 2010.

COURA, Alexandre de Castro; ESCOSSIA, Matheus Henrique dos Santos da. A falácia no direito das minorias: a faceta pragmatista a partir do perfil contramajoritário da Corte. Revista de informação legislativa: RIL, v. 52, n. 207, p. 63-8o, jul./set. 2015. Disponível em: 〈https://www12.senado.leg.br/ril/edicoes/52/207/ril_v52_n207_p63〉. Acesso em I2 de fev. 2021.

CURIA, Luiz Roberto; CÉSPEDES, Livia; ROCHA, Fabiana Dias. Vade Mecum Saraiva. 2i. ed. atual. e ampl. - São Paulo : Saraiva, 2016.

ASSEMBLEIA GERAL DA ONU. "Declaração Universal dos Direitos Humanos". "Nações Unidas", 217 (III) A, I948, Paris, art. I, http://www.un.org/en/universaldeclaration-human-rights/. Acesso em ir de outubro de 2018.

FABER, Marcos Emílio Ekman. Consequências da Segunda Guerra Mundial. Disponível em: 〈http://www.historialivre.com/contemporanea/conguerra2.htm〉. Acesso em of de fevereiro 2019.

GARCIA, Loreley Gomes. Direitos das minorias: democracia universal e direitos particulares. Revista Tesseract. ISSN 1519-2415. Edição Especial 2004. Disponível em: 〈https://www.academia.edu/27767070/Direitos_das_minorias_democracia_universal_e_dir eitos_particulares $>$. Acesso em il de fev. 202I.

HOUAISS, Instituto Antônio, Org. Dicionário Houaiss Conciso. [editor responsável Mauro de Salles Villar]. - São Paulo: Moderna, 2oIr.

JUNIOR, Cássio Marcelo Mochi. A Evolução dos Direitos Humanos. Maringá-PR, 2016.

LEITE, Gisele; CRUZ, Ramiro Luiz Pereira da. O significado da doutrina para a Ciência do Direito. JornalJurid. 24 de abril de 2020. Disponível em: $<$ https://www.jornaljurid.com.br/colunas/gisele-leite/o-significado-da-doutrina-para-aciencia-do-direitor $>$. Acesso em II de fev. 202I.

MARTINS, Argemiro Cardoso Moreira; MITUZANI, Larissa. Direito das Minorias Interpretado: o compromisso democrático do direito brasileiro. Sequência, n. 63, p. 319-352, dez. 
〈https://periodicos.ufsc.br/index.php/sequencia/article/view/2177-7055.2011v32n63p319>. Acesso em 20 de setembro de 2018.

MELANI, Ricardo. Diálogo: primeiros estudos em filosofia, volume único. - 2. ed. São Paulo: Moderna, 2016.

MIRANDA, Eduardo Francisco Alves. O discurso de ódio nas redes sociais: um limite para à liberdade de expressão. Conteudo Juridico, Brasilia-DF: II fev. 2021. Disponivel em: <https://conteudojuridico.com.br/consulta/Artigos/54621/o-discurso-de-dio-nas-redessociais-um-limite-para-liberdade-deexpresso>. Acesso em: II fev. 202I.

MORENO, Jamile Coelho. Conceito de Minorias e Discriminação. Revista USCS - Direito - ano $\mathrm{X} \quad$ - n. $17 \quad$ n. jul./dez. 2009. Disponível em: 〈http://seer.uscs.edu.br/index.php/revista_direito/article/download/888/740>. Acesso em o2 de janeiro de 2019.

NADER, Paulo. Filosofia do Direito. Rio de Janeiro: Forense, 2009.

MARCIEL NETO, Pedro Benedito. Reflexões sobre o estudo do direito. Campinas: Editora Komedi, 2007.

NUNES, S. S. Racismo contra negros: um estudo sobre o preconceito sutil. 227 fls. Tese (Doutorado em Psicologia) - Instituto de Psicologia, Universidade de São Paulo, São Paulo, 2010.

PAULA, Jônatas Luiz Moreira de. Proteção Jurídica das Minorias. Publicação revista e atualizada. Maringá-PR, 2014.

REALE, Miguel. Filosofia do direito. - 19. ed. - São Paulo: Saraiva, 1999.

RIOS, Roger Raupp; LEIVAS, Paulo Gilberto Cogo; SCHÄFER, Gilberto. Direito da Antidiscriminação e Direitos de Minorias: Perspectivas e Modelos de Proteção Individual e Coletivo. Rev. direitos fundam. democ., v. 22, n. I, p. 126-I48, jan./abr. 2017. Disponível em: 〈http://revistaeletronicardfd.unibrasil.com.br/index.php/rdfd/article/download/852/491 > . Acesso em io de fevereiro de 2019.

SANTIAGO, Emerson. O Pacto Internacional dos Direitos Civis e Políticos (1966). Disponível em: <https://www.infoescola.com/direito/pacto-internacional-dos-direitoscivis-e-politicos-1966/>. Acesso em i9 de junho de 2018 .

SERRA, Erica Roberts C. Igualdade e diferença nos direitos humanos. In: BITTAR, Eduardo C. B. (org.). Direitos humanos no século XXI: cenários de tensão. Rio de Janeiro: 
Forense Universitária; São Paulo: ANDHEP; Brasília: Secretaria Especial dos Direitos Humanos, 2008. p. I8-26.

SILVA, Flavia Martins André da. Direitos Fundamentais (Constitucional). Artigo jurídico - DireitoNet. I6/maio/2006. Disponível em: 〈https://www.direitonet.com.br/artigos/exibir/2627/Direitos-Fundamentais〉. Acesso em Io de fev. 2021. 